\title{
Oculopharyngodistal myopathy
}

INSERM

\section{Source}

INSERM. (1999). Orphanet: an online rare disease and orphan drug data base.

Oculopharyngodistal myopathy. ORPHA:98897

Oculopharyngodistal myopathy is a rare, genetic neuromuscular disease characterized by progressive external ocular, facial and pharyngeal muscle weakness, leading to variable degrees of ptosis, ophthalmoparesis, facial muscle atrophy, dysarthria and dysphagia, as well as distal muscle weakness and atrophy of lower and upper extremities. Respiratory muscle involvement is common, but sensorineural hearing loss, asymmetrical extremity weakness and severe proximal weakness are rare. 